\title{
Prevention of Childhood Obesity: A Position Paper of the Global Federation of International Societies of Paediatric Gastroenterology, Hepatology and Nutrition (FISPGHAN)
}

\author{
${ }^{*}$ Berthold Koletzko, ${ }^{\dagger}$ Mark Fishbein, ${ }^{\ddagger}$ Way S. Lee, ${ }^{\S}$ Luis Moreno, ${ }^{\prime}$ Nezha Mouane, \\ "Marialena Mouzaki, and ${ }^{\#}$ Elvira Verduci
}

\begin{abstract}
Global childhood obesity increased more than 8-fold over 40 years, inducing a very large personal, societal, and economic burden. Effects of available treatments are less than satisfactory; therefore, effective prevention is of high priority. In this narrative review, we explore preventive opportunities. The available evidence indicates large benefits of improving nutrition and lifestyle during early life, such as promoting breast-feeding and improving the quality of infant and early childhood feeding. Promoting healthy eating patterns and limiting sugar-containing beverage consumption from early childhood onwards are of great benefit. Regular physical activity and limited sedentary lifestyle and screen time alone have limited effects but are valuable elements in effective multicomponent strategies. The home environment is important, particularly for young children, and can be improved by educating and empowering families. School- and community-based interventions can be effective, such as installing water fountains, improving cafeteria menus, and facilitating regular physical activity. Reducing obesogenic risk factors through societal standards is essential for effective prevention and limiting socioeconomic disparity; these may comprise food, drink, and physical activity standards for day cares and schools, general food quality standards, front-of-pack food labeling, taxation of unhealthy foods, restriction of food advertisements to children, and others. Effective prevention of childhood obesity is not achieved by single interventions but by integrated multicomponent approaches involving multiple stakeholders that address children, families, and societal standards. Pediatricians and their organizations should be proactive in supporting and empowering families to support their children's health, and in promoting societal measures that protect children.
\end{abstract}

Key Words: children, nutrition, obesity prevention, physical activity, public health policy

(JPGN 2020;70: 702-710)

hildhood obesity induces very high personal, societal, and economic burden throughout the world. Childhood obesity coexists together with micronutrient deficiencies and with stunting in individuals, families, and populations, which is commonly referred to as double-burden of malnutrition $(1,2)$. During the last 4 decades the worldwide prevalence of childhood obesity has increased more than 8-fold among 5- to 19-year olds, and it

Received March 9, 2020; accepted March 12, 2020.

From the *Dr. von Hauner Children's Hospital, LMU_Ludwig-Maximilians-Universität Munich, Munich, Germany, the †Feinberg School of Medicine at Northwestern University, Chicago, IL, the $\ddagger$ Department of Pediatrics, Faculty of Medicine, University of Malaya, Kuala Lumpur, Malaysia, the §Faculty of Health Sciences, Zaragoza, Spain, the |Children's Hospital Ibn Sina, University Mohammed V Souissi (UM5S), Rabat, Morocco, the ๆCincinnati Children’s Hospital Medical

\section{What is known?}

- Childhood obesity prevalence markedly increased over the last four decades and induces a very high personal, societal and economic burden.

- Since effects of available obesity treatments are less than satisfactory, prevention is of high priority.

\section{What is new?}

- Effective prevention of childhood obesity requires an integrated multicomponent approach addressing individual behaviour and diet, family habits, educational institutions, and societal standards.

- Preventive effects are largest in early life, with marked risk reduction through improved infant and young child feeding.

- Promoting the health of disadvantaged children, both in low- and low-medium income countries and in disadvanted groups in affluent countries, requires particular attention.

- Paediatricians and their organisations should actively support and empower families and promoting societal measures to protect the health of children.

continues to rise on a global basis (1). Although the increase of mean body mass index (BMI) has flattened in a number of European and other high-income countries as well as the Asia-Pacific region, obesity prevalence has continued to increase since 2000 in most countries of the Organization for Economic Co-operation and Development) and has accelerated in east and south Asia for both sexes, and southeast Asia for boys $(1,2)$. It is estimated that in 2016, 50 million girls aged 5 to 19 years and 74 million boys worldwide will be obese, with serve adverse consequences for the wellbeing of individuals, for associated costs and for society (1). Overweight and

Center, Cincinnati, OH, and the \#Department of Pediatrics, San Paolo Hospital, University of Milan, Milan, Italy.

Address correspondence and reprint requests to Berthold Koletzko, Dr. von Hauner Children's Hospital, LMU—Ludwig-Maximilians-Universität München, Lindwurmstr. 4, D-80337 München, Germany (e-mail: office.koletzko@med.lmu.de).3. 
obesity in childhood are serious threats for health and well-bring due to increased risks for metabolic disorders, insulin resistance and diabetes, cardiovascular diseases, nonalcoholic steatohepatitis, some forms of cancer, musculoskeletal, and psychological disorders and markedly increased mortality (3). The World Health Organization concluded that obesity currently is the fifth leading cause of global deaths and responsible for $44 \%$ of the burden of diabetes mellitus, $23 \%$ of ischemic heart disease, and $7 \%$ to $41 \%$ of certain cancers, with a large impact on health care costs, loss of productivity, and the global economy (4). There are indications for marked inter-individual variations of the adverse health impact of similar BMI elevations, which may be due to variation in genotype and/or other variables modifying risk. Better understanding of these influencing co-variables might lead to more targeted preventive approaches in the future. Changes in socioeconomic disparity occurred over time, as documented, for example, in the United Kingdom: children and adolescents from lower socioeconomic groups had lower body weight when born until 1970, whereas among those born later a much higher obesity risk emerged and widened over time (5). These substantial changes indicate the impact of societal changes on child and adolescent obesity and the insufficiency of established policies in protecting the health of socioeconomically disadvantaged children.

Unfortunately, our ability to effectively treat childhood obesity is less than satisfactory, and treatment tends to be costly (6-8). Therefore, the development, evaluation, and implementation of cost-effective prevention strategies are of high priority (9). The need for childhood obesity prevention was proposed already many decades ago even though little information on possible effects was available at that time (10). More recently, refined prevention strategies have been developed and evaluated. A current Cochrane review including 153 randomized controlled trials evaluating obesity prevention strategies in children, mostly from high-income countries, concluded that particularly interventions addressing both diet and physical activity can reduce the risk of obesity, but the mean effect sizes are small and not satisfactory (6). Of interest, the observed effect sizes were greater in young children aged 0 to 5 years than in older children, indicating a potentially larger preventive potential at early ages. Studies on long-term effects on body weight and later health benefits are, however, lacking.

The aim of this position paper of the global Federation of International Societies of International Societies of Pediatric Gastroenterology, Hepatology and Nutrition (FISPGHAN) is to highlight applicable opportunities and priorities for preventing childhood obesity, building on preceding comments of FISPGHAN expert teams on this topic $(11-13)$ and the World Health Organization report on ending childhood obesity (4).

\section{DEVELOPMENT OF THIS POSITION PAPER}

The council of FISPGHAN identified the topic of childhood obesity prevention as a global priority issue to be addressed by an expert team, with the goal to describe feasible actions that may contribute to reducing obesity risk. The FISPGHAN member societies nominated experts in the field. The FISPGHAN council selected and appointed members of the expert team and a chair. The team worked together using phone conferences and digital communication. The subtopics included in this manuscript were chosen through a consensus of the experts involved. Each co-author drafted the first version of 1 section in the format of a narrative review, based on an electronic literature search performed by the respective author. These first drafts were then jointly revised by all authors, additional considerations and references were added, and these were combined to a final manuscript that was reviewed and approved by all authors. This manuscript was reviewed by the FISPGHAN council and approved with some modifications as a FISPGHAN position paper.

\section{EARLY LIFE FACTORS MODULATE LIFELONG OBESITY RISK}

During periods of developmental plasticity in early life, environmental and nutritional cues can metabolically program long-term body size and body composition, and the risk of obesity, adiposity, and associated noncommunicable diseases (NCDs) (1416). The potential of early interventions for life-long promotion of health and prevention of NCDs is of considerable interest in view of very high and rising global burden of NCDs (17-21). Prenatal lifestyle and nutrition choices provide an opportunity for attenuating the obesity risk of the offspring (15). Maternal BMI at the time of conception is a particularly strong predictor of offspring obesity, whereas weight gain during pregnancy has little effect (22). Therefore, health care providers should encourage women who wish to and may get pregnant to approach normal body weight before conception (15).

Infant feeding and early weight gain trajectories can markedly modulate long-term obesity risk $(23,24)$. In a first large study on the effects of breast-feeding, obesity prevalence at early school age among 9357 children was shown to be much higher in children who were never breast-fed than in those who had been breast-fed, with an inverse dose-response relation between the duration of breast-feeding and later obesity prevalence (25). After adjusting for potential confounding, breast-feeding remained a significant protective factor against later overweight (odds ratio [OR] $0.79,0.68-0.93$ ) and obesity (OR $0.75,95 \%$ confidence interval $[\mathrm{CI}] 0.57-0.98)$. The protective effect of breast-feeding
As member of the German National Breastfeeding Committee and the national program Becoming Breastfeeding Friendly, chair of the German Paediatric Society Nutrition Committee, and President Elect of the International Society for Research in Human Milk and Lactation, B.K. tends to be biased towards breast-feeding. LMU-Ludwig-MaximiliansUniversität Munich and its employee B.K. benefit from support for scientific and educational activities from the European Commission, FP7 Programme Early Nutrition-289346 and H2020 Programmes DYNAHEALTH-633595 und Lifecycle-733206, the European Research Council Advanced Grant META-GROWTH ERC-2012-AdG-no. 322605, the Erasmus Plus Programmes Early Nutrition eAcademy Southeast Asia573651-EPP-1-2016-1-DE-EPPKA2-CBHE-JP and Capacity Building to Improve Early Nutrition and Health in South Africa-598488-EPP-12018-1-DE-EPPKA2-CBHE-JP, the EU Interreg Programme Focus in CD-CE111 and the European Joint Programming Initiative Project NutriPROGRAM, the German Ministry of Education and Research, Berlin (Grant Nr. 01 GI 0825), German Research Council (Ko912/121 and INST 409/224-1 FUGG), University of Munich Innovation
Initiative, the US National Institutes of Health, the Government of Norway, and different health care and nutrition companies, predominantly as part of publically funded research projects supported by the European Commission or German government. W.S.L. received traveling grants from Danone Nutrition (Malaysia), Nestle Nutrition (Malaysia), and Abbott Nutrition (Malaysia). E.V. reports support from Nutricia Italia Spa, Nestle Health Science-Vitaflo Italy, FoodAR srl Italy, PIAM Pharma, and Integrative Care. All authors declare no conflict of interest in relation to the topic of this manuscript, that is, circumstances that involve the risk that the professional judgment or acts of primary interest may be unduly influenced by a secondary interest.

DISCLAIMER: FISPGHAN is not responsible for the practices of physicians and provides position papers as indicators of best practice only. Diagnosis and treatment is at the discretion of physicians.

Copyright (1) 2020 by European Society for Pediatric Gastroenterology, Hepatology, and Nutrition and North American Society for Pediatric Gastroenterology, Hepatology, and Nutrition

DOI: $10.1097 / \mathrm{MPG} .000000000002708$ 
on later obesity has been replicated in numerous other studies summarized in several meta-analyses showing that breast-feeding is associated with a modest but consistent risk reduction for later obesity by $22 \%(26), 15 \%(27), 12 \%$ (28), and $22 \%$ (29), respectively. The impact of breast-feeding on later obesity, however, continues to be debated, because the data are based on observational studies with a considerable risk of residual confounding, even after adjusting for measurable influencing factors. A secondary analysis of a clusterrandomized trial designed to test the effectiveness of the 10 steps for promoting breast-feeding in obstetrical hospital settings in Belarus, breast-feeding duration, and the duration of exclusive breast-feeding did not reduce obesity risk in school age and adolescence (30,31). Of importance, this study did not compare breast- and formula-fed infants but only explored modest differences in breast-feeding duration, with an inadequate statistical power to detect effects on later overweight (statistical power $<10 \%$ ) (32). Although randomization of infants to breast- and formula feeding cannot be performed, studies on underlying mechanisms for the obesity preventive effect of breastfeeding may underpin the arguments for a causal preventive effect of breast-feeding (33).

One mechanism appears to be the attenuating effect of breast-feeding on high rates of weight gain, when compared to feeding conventional bottle milk $(34,35)$. Rapid weight gain in infancy and the second year of life is consistently associated with increased adjusted odds for later obesity $(36,37)$. The analysis of combined data of 6708 children from 11 high-income countries showed that breast-feeding for at least 3 months is associated with a significantly lower likelihood of rapid weight gain and of an elevated BMI until school age, as well as of high BMI, skinfold thickness, and fat mass up to the age of 20 years (38). Given that a lack or short duration of full breast-feeding is associated with rapid early weight gain and increased long-term obesity risk in adulthood, protection, promotion, and support of breast-feeding remains a very important priority for pediatricians and other health care professionals.

Weight gain depends on dietary energy supply, and avoiding overfeeding and an excessive energy intake contributed to preventing high rates of weight gain. An additional modulating factor is the macronutrient composition of infant feeds. Compared to human milk, conventional infant formulae traditionally have provided a much higher protein supply $(39,40)$. Randomized clinical trial evidence demonstrates that infant feeding with formula with a reduced protein supply, more similar to breast milk, normalizes weight gain in early childhood, and it also markedly reduces the adjusted odds for obesity at early school age by as much as 2.6 -fold (95\% CI 1.33, 5.10), compared to conventional formula with a high protein content $(41,42)$. This strategy also significantly reduced body fatness at school age (43). In a small study, Putet et al (44) randomized 154 infants to formula feeding with a smaller difference in protein intake for only the first 4 months of life. At several time points during the first 60 months children receiving the lower protein intake during the first 4 months showed lower body weight, length, and head circumference but no differences were detected for body composition and obesity prevalence with the limited statistical power of this study. Another trial that randomized healthy 1-yearold children to standard cows' milk or a reduced protein milk for the second year of life showed that a lower protein intake reduced body fatness at the age of 2 years (45). In their systematic review on interventions to reduce childhood obesity risk during the first 1000 days of life, Blake-Lamb et al (46) concluded that proteinenriched formula increase childhood obesity risk.

We conclude that improved infant feeding strategies can have a greater impact than any other obesity prevention strategy evaluated in children. Therefore, avoiding excessive protein intakes in infancy through effective promotion of breast-feeding, use of infant formula with lower protein contents, and avoidance of providing unmodified cows' milk as a drink in the first year of life has been recommended but requires further evaluation $(15,33,47)$. The effects of limiting protein intake in early life should be further explored and also include studies in populations in lowand low-medium-income countries.

The effects of complementary feeding on later obesity have been less well studied. Although timing of introducing solids between 4 and 6 months or after 6 months does not seem to affect growth and later obesity risk, introduction of solids before 4 months of age increased the risk, particularly in formula-fed children (48). Complementary feeding patterns with high intakes of sugar and of animal protein were associated with increased risk of obesity at school age, but the impact of the quality of complementary food on short-term growth and later obesity risk should be elucidated further.

A recent systematic review identified 6 randomized trials with multicomponent interventions in infancy targeting promotion of breast-feeding (4 trials), responsive infant feeding (2), and promotion of healthy diets that reported BMI reductions at the end of the intervention, although the 2 trials with follow-up to toddler age did not find a persistent significant effect (49).

Together, the available data demonstrate the large potential of improving nutrition and lifestyle in early life for risk reduction of later obesity, which should consider the whole period of preconception, pregnancy, infancy, and early childhood as a window of opportunity.

\section{PROMOTING HEALTHY EATING AND DRINKING IN CHILDHOOD}

After infancy, no single dietary nutrient alone has been consistently associated with the development of overweight and obesity; rather dietary habits and the choice of portion sizes and dietary patterns appear to be predictive $(50,51)$. For example, preventive effects have been associated with a Mediterranean diet pattern (52). The Mediterranean diet is rich in plant-based foods with low energy density and dietary fiber, such as cereals, fruits, vegetables, legumes, tree nuts, seeds, and olives, along with high to moderate intakes of fish; a moderate consumption of eggs, poultry, and dairy products; a low consumption of red meat; and the use of vegetable oils high in unsaturated fats such as olive oil. The observed decline in adherence to the Mediterranean diet has been associated with an increase in NCDs, also in children (53), whereas increasing adherence to a Mediterranean dietary pattern was associated with a favorable body composition in school-aged children (54) and a favorable BMI change among adolescents (55). The Nordic diet, a similar dietary pattern rich in foods traditionally consumed in Scandinavian countries, including fiber-rich plant-based foods such as rye, apples, berries, cabbage, and root vegetables as well as fish (56), was proposed to also facilitate achieving a normal body weight and health, but further studies are needed in childhood.

Risk increasing dietary habits associated with excessive childhood weight gain that predicts an increased risk of subsequent overweight and obesity $(33,38,57)$ are characterized by poor diet quality; high intakes of processed and fast foods, unhealthy snacks, and sugar-sweetened beverages; high total energy density; high intakes of saturated fats, salt, and sugar, and a low fiber intake $(51,54)$. A current Cochrane review of randomized intervention trials on obesity prevention in children concluded that combined interventions addressing both diet and physical activity have a preventive benefit in children aged 0 to 5 years; that dietary interventions may be beneficial in young children aged 0 to 5 years, whether there is only weaker evidence for benefit of dietary intervention (6).

High intakes of sugar-containing beverages in children and adolescents have been consistently linked to an increased 
overweight and obesity risk, and randomized intervention trials documented marked benefits of strategies that reduce their consumption (58). Preschool- and school-based programs aiming at changing eating and drinking behavior may be beneficial (59). Governments and health care service providers should provide consistent information on the benefits of replacing sugar-containing beverages by water and other nonsweetened beverages, to ban advertising of such products to children and their distribution in preschools and schools, and to consider taxation, because this may contribute to reducing their consumption among children (58). In addition, interventions targeting the food environment around schools are promising (60). Supporting health promoting dietary patterns and habits should begin very early in life because unhealthy dietary patterns established in infancy and early childhood tend to persist to older age and may thus adversely affect long-term health (61).

\section{PROMOTING REGULAR PHYSICAL ACTIVITY IN CHILDREN AND ADOLESCENTS, WHILE REDUCING SCREEN TIME AND SEDENTARY LIFESTYLE}

Physical activity is the main modifiable component of human total energy expenditure. Moderate and vigorous physical activities appear to be the most relevant components. In cross-sectional and prospective analyses in children and adolescents, moderate to vigorous physical activity (MVPA) was associated with lower adiposity $(62,63)$. Causality may, however, be bidirectional because intervention studies do not show good efficacy regarding indicators of increased physical activity. In children aged 0 to 5 years, a metaanalysis including 21 studies showed only a very small mean difference for MVPA between intervention and control groups of $2.88(95 \% \mathrm{CI}=1.54,4.23)$ minutes/day (64). In children aged 5 to 12 years, a meta-analysis of 19 family-based interventions also showed only a small effect in favor of the intervention group (standardized mean difference: $0.41 ; 95 \%$ CI $0.15-0.67)$ (65). In adolescents older than 10 years, randomized controlled trials conducted in the school setting showed pooled effect sizes that were small and nonsignificant for both total physical activity and moderate-to-vigorous physical activity (66). Recently, active video games have been proposed as a strategy to increase physical activity; however, there is currently insufficient evidence to recommend their use within schools (67). The promotion of school environments that facilitate and encourage regular physical activity appears as a promising strategy for lowering the risk of obesity (68).

With regard to sedentary behaviors, a recent long-term study showed that television viewing of at least 4 hours/day versus no television at the age of 3 to 5 years was associated with an increased later risk of overweight and obesity (69). The ORs were 1.61 (95\% CI: $1.20,2.17)$ at age 5 years, $1.46(95 \% \mathrm{CI}: 1.14,1.86)$ at age 10 years, $1.31(95 \%$ CI: $1.00,1.70)$ at age 18 years, and $1.32(95 \%$ CI: $1.10,1.59)$ in adulthood (69). Interventions aiming at reducing sedentary behaviors appear to be effective, with a meta-analysis of 34 randomized intervention trials showing a pooled reduction frombaseline of $-20.44 \mathrm{~min} /$ day (95\% CI: -30.69 ; -10.20$)(70)$. A systematic review of interventions targeting sedentary behaviors in children showed a significant but small reduction of BMI and BMI $z$ score; however, there was an encouraging greater effect in children with overweight or obesity and with multicomponent interventions (targeting both sedentary and other behaviors) (69).

Eating while watching TV was also positively associated with overweight $(\mathrm{OR}=1.28 ; 95 \% \mathrm{CI}: 1.17,1.39)$ (71). Reallocating 30 minutes of sedentary time into 30 minutes of MVPA was associated with less waist circumference, trunk fat mass, and total body fat mass after 20 months (72). The direction of the causality of the association is, however, not entirely clear, given that a high fat mass index in children at baseline was associated with lower physical activity and higher sedentary time after 200 days, but not vice versa, even in normal-weight children (73).

Although promotion of physical activity by itself is not sufficiently effective for preventing obesity, promoting physical activity and reduced sedentary behaviors may be one valuable element in effective multicomponent strategies for childhood obesity prevention (74). Environments at home, at school, and at the community level that facilitate and encourage physical activity, outdoor activity and play, and social interactions should be promoted, whereas using screen devices at meal times and in bedrooms should be avoided (75).

\section{STRATEGIES FOR EDUCATION, MOTIVATION, AND EMPOWERMENT OF FAMILIES}

The home environment greatly influences young children. Parents may serve as positive role models to their children regarding healthy nutrition, physical activity, and emotional and social health. Interventions targeting parenting style and parental child feeding practices during early childhood may positively affect children's eating practices. Parenting style is defined as a "constellation of attitudes toward the child that are communicated to the child and create an emotional climate in which the parent's behaviors are expressed" (76). Authoritative parenting is characterized by a parent's control over their child's behaviors while also displaying warmth and responsiveness; authoritarian parenting is characterized by high control and low levels of warmth and responsiveness. The authoritative style is favored to provide healthier trajectories including lower risk of obesity, higher physical activity, and lower sedentary behaviors $(77,78)$. Adverse parental child feeding practices include restriction, pressure to eat, and monitoring. Increased awareness and avoidance of these practices is crucial, particularly with regard to food restriction: it appears to have the unintended consequence of increasing rather than decreasing the child's preference for and intake of restricted items (79). Restrictive behaviors decreased the child's self-control over their eating behaviors and increased eating in the absence of hunger. Children who are more restricted tend to have a higher BMI (80). An example of a successful program is the Feeding Dynamic Intervention targeting caregivers of 2 to 5 year old children, which may curb parental restrictiveness and pressuring in their feeding practices (81).

Children of all age groups appear to have less obesogenic behaviors when living in households that enforce family rules, particularly those that limit duration of screen time (television, computer and mobile device use, and video games). The benefits appear to be related to promoting self-regulation and are manifested by reducing consumption of fast foods and soft drinks, while increasing consumption of fruits and vegetables and vigorous activity (82).

\section{CHILDCARE, SCHOOL, AND PRIMARY CARE-BASED OBESITY PREVENTION PROGRAMS IN CHILDREN}

Because obesity in adults is difficult to treat through changes in the lifestyle, prevention of obesity in early childhood is a key strategy for obesity prevention. Two crucial aspects of obesity prevention in children are early childhood and school-based interventions (83). Targets of childcare-based programs should include improving the nutritional quality of food provided such as fruits and vegetable, increasing intake of water and reducing intake of sugarsweetened beverages, promoting physical activity, and reducing screen time. Great care must be taken to avoid potential harm, and 
particularly stigmatization and blame and shame of overweight and obese children needs to be avoided. There is emerging evidence from high-income countries showing benefits of obesity prevention programs targeting children attending early childcare settings, such as preschool or kindergartens $(59,84,85)$. For example, an Australian obesity prevention project promoting healthy eating and active play among children younger than 5 years showed that children in the intervention group had a significantly lower intake of packaged snacks, fruit juice, and cordial and a higher vegetable consumption as compared to the control group (86). A behavioral intervention program in kindergarten settings in Germany achieved a lasting increase of the consumption of vegetables, fruits, and water instead of sugary drinks in the family home, as compared to a control group (59).

Education settings (preschool, primary, and secondary schools) are popular settings for intervention as most children attend school and many schools have existing infrastructure to support the implementation of interventions (87). Similar to child care-based program, school-based intervention program should also focus on cultivating healthy eating habits and promoting physical activity at school. In addition, it is important to engage the involvement of both parents and teachers. Parental involvement is important in achieving sustained behavioral change in preschoolaged children. Evidence shows that successful interventions have multiple components and are adapted to the local context. A recent narrative review of 14 randomized trials that were school $(n=11)$ or community (3) based concluded that benefits on BMI or body composition can be achieved, even though the effect sizes tend to be modest, and there is a lack of information on long-term effects. Of importance, a recent health economic analysis suggested costeffectiveness even of relatively small population level reductions in BMI if intervention effects can be maintained. An mean reduction in BMI $z$ score by -0.13 in children aged 2 to 5 years, observed in a scoping review of systematic reviews, would result in 36,496 health-adjusted life years saved and health care cost savings of approximately 301 million Australian dollar if modeled over the lifetime (88). Similarly, for the German population an infancy intervention reducing BMI $z$ score by -0.20 at the age of 2 years was calculated to save $750 €$ of health-related costs per person over a lifetime, discounted at 3\% (89). If this intervention reaches only about $20 \%$ of the German infant population, the resulting cost savings are calculated as 3.5 billion $€$ (89).

Benefits of approaches changing the child's environment, such as installation of water fountains to reduce the consumption of sugar-containing drinks and changes of cafeteria menus have been reported, potentially in combination with health education lessons, although these were rated less sustainable (90). Culturally and environmentally appropriate programs are more likely to be implemented and sustained (91). More attention should be devoted to developing and evaluating setting-based interventions addressing obesity prevention in low- and low-medium-income countries. It is also important to realize that sustained efforts are necessary to make community-based interventions successful. Often, programs lasting only for 1 to 2 years may result in a change in eating behavior but not in effects on BMI or BMI $z$ score (83).

\section{COMMUNITY-BASED STRATEGIES}

Community organizations have arisen to provide resources for obesity prevention. Given that no one organization is likely to have sufficient expertise in health education, environmental change, institutional decision making, and policy change, community coalitions - comprising representatives of diverse communities of geography, identity, and practice-may play a key role in applying a social-ecological approach to obesity prevention. These organizations pursue 4 major categories of action: increase healthy options, reduce deterrents to healthy behaviors, build community capacity, and improve social and economic resources for individuals and families. A few selected examples among the numerous initiatives include the Be Active Eat Well program in Australia, the Consortium to Lower Obesity in Chicago Children (CLOCC), and Fighting Obesity Reaching Healthy Weight Among Residents of DuPage (FORWARD DuPage) in the USA.

The Australian Be Active Eat Well program was a multifaceted community capacity-building program promoting healthy eating and physical activity for children aged 4 to 12 years in the town of Colac. Anthropometric and demographic data were collected in 1001 children in 4 preschools and 6 primary schools at baseline and 3 years later, with a follow-up rate of $84 \%$ (92). The comparison sample was a stratified random selection of preschools and primary schools from other parts of the same Australian state $(n=1183)$. Children in Colac children had significantly lower increases in body weight (mean: $-0.92 \mathrm{~kg}$ ) and BMI $z$ score $(-0.11)$ than comparison children, adjusted for baseline variables. Of importance, in Colac the anthropometric changes were not related to 4 indicators of socioeconomic status (SES), whereas in the comparison group 19 of 20 such analyses showed significantly greater gains in anthropometry in children from lower SES families. These observations point to the potential of community-based approaches to reduce obesity risk increasing health inequalities.

The American CLOCC program of Ann and Robert H Lurie Children's Hospital of Chicago comprises more than 3000 individuals representing over 1200 organizations working on childhood obesity prevention across Illinois and throughout the country. Working together, CLOCC staff and partners have implemented numerous programs, projects, and policy initiatives to increase individual and family knowledge about healthy lifestyles; strengthen organizational and institutional practices to support healthy eating and physical activity; and improve environments so that healthy food and physical activity are widely available where people, and especially children, live, work, learn, and play (93).

The FORWARD DuPage mission is "to lead DuPage County, through a broad-based community coalition, in promoting effective and sustainable policy, systems, and environmental strategies for children and families to achieve a healthy weight.' The coalition has more than 1400 members and consists of volunteers and professional practitioners. Among FORWARD DuPage's achievements are improved pedestrian and bicyclist transportation networks; healthy, sustainable food systems, expansion of school and community gardens, farmers' markets, and changes promoting health in early childcare facilities, schools, and businesses. FORWARD is currently establishing specific strategies for county-wide schools, worksites, and early childhood settings through education, tools, resources, and expertise (94).

Little information is available on community-based prevention strategies in low- and low-medium-income countries (95), which should be developed further.

\section{SETTING SOCIETAL STANDARDS FOR EFFECTIVE OBESITY PREVENTION}

Research has shown that adherence of patients and families to obesity prevention guidelines is extremely limited and highly dependent upon socioeconomic factors $(96,97)$. In addition, early interventions aimed at promoting a healthy lifestyle have only limited long-term impact on obesity risk factors, such as dietary intake, physical activity, and screen time (98). Sustainability of successful obesity prevention strategies requires funding, community engagement, and leadership, among other factors (99). 
Therefore, societal standards need to be set to support families in their efforts to prevent obesity and to reduce socioeconomic disparity of childhood obesity risk.

Societal aspects of obesity prevention include promotion of a healthy lifestyle through implementation of food quality standards (eg, elimination of sugar-sweetened beverages and unhealthy foods, and mandatory involvement in physical activities at day cares and schools) and development of an infrastructure that encourages healthy dietary intake and physical activity (100). The latter refers to the availability of and access to healthy but noncostly foods (eg, water, fruits, vegetables), as well as safe spaces where children can be active (eg, parks, community gyms/pools, etc.). Provision of education around healthy lifestyle choices at school and in the community, as well as elimination of barriers to expressing healthy preferences such as advertisements promoting unhealthy habits, are additional examples of measures that can be taken at the societal level. The literature on the efficacy of programs aimed at addressing some of the aforementioned risk factors has generated conflicting results. A meta-analysis of 115 predominantly North American studies showed that school-based interventions focusing on physical activity (alone or in combination with dietary changes) were effective in preventing obesity in children 2 to 18 years of age (95). In contrast, a large study from multiple Europe countries showed that combined interventions aimed at facilitating a healthy lifestyle at school, home, and the community had little impact on preventing childhood obesity (101). Socioeconomic and cultural differences may have contributed to the discrepant results of these studies.

Television (TV) advertising can influence food preferences and consumption, particularly in children from lower socioeconomic groups that tend to spend more spent watching TV. Brown et al (102) evaluated the effects of legislation to restrict TV advertising for foods and beverages high in fat, sugar and salt until 9:30 pm for the Australian population. The authors concluded that restricting TV advertising is likely to be cost saving. The most disadvantaged socioeconomic group reached 1.4 times higher total cost savings and 1.5 times higher health benefits, with savings of 17,512 health adjusted life years and 126.3 million Australian dollars, compared to 11,321 HALYs and 90.9 million Australian dollars saved in the least disadvantaged socioeconomic group.

Societies can also motivate consumers to make healthier dietary choices by leveraging on the impact of cost on purchasing behaviors. Generally, healthy foods tend to be more expensive, may require more time to prepare, and have a shorter shelf life as processed obesogenic foods. In today's society and particularly in the context of socioeconomic deprivation, these factors often determine consumers' choices, even if their original intent was to be healthy (103). This knowledge, however, can and has been leveraged to benefit consumers. Some countries implemented food taxes to motivate the public to limit the consumption of foods that exert negative health outcomes, such as sugar sweetened beverages or foods high in saturated fats or salt $(104,105)$. This approach is effective in changing purchasing behaviors, particularly of subjects who are young and of a lower SES (103). In Mexico, a country in transition, the introduction of a 1-peso-per-liter tax to sugar sweetened beverages achieved sizable and sustained reductions in obesity and diabetes with a calculated average BMI reduction of $0.15 \mathrm{~kg} / \mathrm{m}^{2}$ or $2.54 \%$ reduction in obesity prevalence. The largest effects occurred among people in the lowest level of SES and in young adults (106). Interestingly, informing consumers about price increases further enhances the effectiveness of this intervention (107). Taxation of not only unhealthy food items, but also unhealthy portion sizes, has the potential to rapidly alter consumer behaviors in a beneficial manner.

Beyond cost, food labeling can also affect purchasing behaviors (103). Research on the topic has revealed that simple, clear, color-coded, and easy to interpret front-of-pack food labeling is effective in improving selection of healthier choices (108). Of importance, simple color-coded front-of-pack food labels are also effective in population groups with increased risk characterized by low levels of income or education, or high BMI (109). Mandatory labeling of foods can have an additional beneficial impact on those at risk by motivating manufacturers and restaurant chains to produce and sell healthier products (110). Examples from across the globe have underscored the impact that food labeling has on improving the quality of the food that is available to consumers (103).

\section{CONCLUSIONS}

- Effective prevention of childhood and adolescent obesity cannot be achieved by single interventions but requires an integrated multicomponent approach involving multiple stakeholders that empowers individual children and their families and reduces obesogenic risk factors in their environment through societal standards (Fig. 1).

- Increased understanding of developmental early origins of long-term obesity risks provides opportunities for marked risk reduction through improved infant and young child feeding. Promotion and support of breast-feeding are a very important priority for pediatricians and other health care professionals.

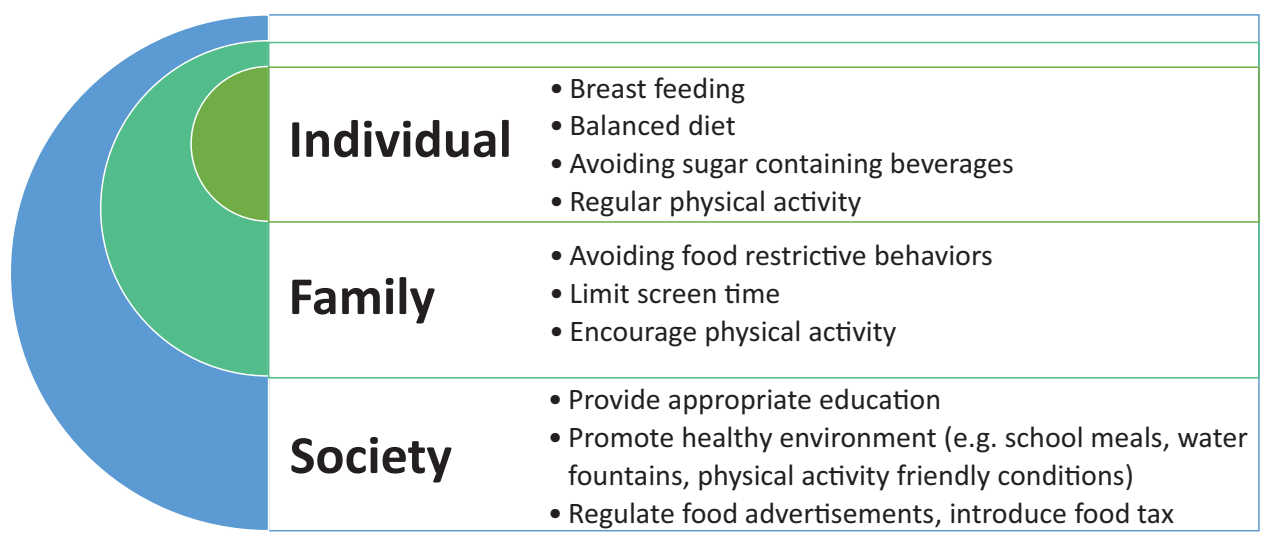

FIGURE 1. Effective prevention of childhood obesity cannot be achieved by single interventions but requires an integrated multicomponent approach involving multiple stakeholders that empowers individual children and their families and reduces obesogenic risk factors in their environment through societal standards. 
In addition, infant feeding without excessive protein supply should be promoted.

- Healthy eating habits and food choices and the promotion of drinking water instead of sugar-containing beverages reduce risk and should be promoted from early childhood onwards, given that dietary patterns established in early childhood tend to persist to older ages.

- Regular physical activity and limitation of screen times and sedentary behavior should be promoted.

- Families should be educated and empowered to act as positive role models for their children on healthy eating, physical activity, and health.

- Educational institutions for children from early day care to secondary schools and other settings regularly attended by children (eg, sports facilities) should set and implement standards that proactively promote healthy eating and drinking by education and by creating healthy food environments, including standards for healthy school meals and the elimination of unhealthy snacks and sugar-containing beverages from educational institutions, and that promote regular physical activity and limit sedentary behavior.

- Societal standards that protect the health of children and adolescents should be established, which may include easy to understand color-coded front-of-pack labeling of food products, price incentives for healthy food choices, for example, through taxation of unhealthy foods, banning of advertising unhealthy foods to children, promotion of barrier free opportunities for regular physical activities, and multistakeholder collaboration for childhood obesity prevention in communities and other settings.

- Particular attention should be devoted to promoting the health of disadvantaged children, both in low- and low-mediumincome countries and in disadvantaged groups in affluent countries

- Pediatricians and their organizations should take an active role in supporting and empowering families to implement steps that support the health of their children, and in promoting societal measures that protect the health of children.

\section{REFERENCES}

1. NCD Risk Factor Collaboration. Worldwide trends in body mass index, underweight, overweight, and obesity from 1975 to 2016: a pooled analysis of 2416 population-based measurement studies in 128.9 million children, adolescents, and adults. Lancet 2017;390: $2627-42$.

2. Organisation for Economic Co-operation and Development (OECD). Obesity Update 2017. OECD; 2017.

3. Global BMI Mortality CollaborationDi Angelantonio E, Bhupathiraju ShN, Wormser D, et al. . Body mass index and all-cause mortality: individual-participant-data meta-analysis of 239 prospective studies in four continents. Lancet 2016;388:776-86.

4. Commission on Ending Childhood Obesity. Report of the Commission on Ending Childhood Obesity. Geneva, Switzerland: World Health Organization; 2016.

5. Bann D, Johnson W, Li L, et al. Socioeconomic inequalities in childhood and adolescent body-mass index, weight, and height from 1953 to 2015: an analysis of four longitudinal, observational, British birth cohort studies. Lancet Public Health 2018;3:e194203.

6. Brown TJ, Mead E, Ells LJ. Behavior-changing interventions for treating overweight or obesity in children aged 6 to 11 years. JAMA Pediatr 2019;173:385-6.

7. Ells LJ, Rees K, Brown T, et al. Interventions for treating children and adolescents with overweight and obesity: an overview of Cochrane reviews. Int J Obes (Lond) 2018;42:1823-33.
8. Elvsaas IKO, Giske L, Fure B, et al. Multicomponent lifestyle interventions for treating overweight and obesity in children and adolescents: a systematic review and meta-analyses. J Obes 2017;2017: 5021902.

9. Weihrauch-Bluher S, Kromeyer-Hauschild K, Graf C, et al. Current guidelines for obesity prevention in childhood and adolescence. Obes Facts 2018;11:263-76.

10. Wright FH. Prevention of obesity in childhood. Clin Pediatr 1963;2:353-9.

11. Koletzko B, Girardet JP, Klish W, et al. Obesity in children and adolescents worldwide: current views and future directions-Working Group Report of the First World Congress of Pediatric Gastroenterology, Hepatology, and Nutrition. J Pediatr Gastroenterol Nutr 2002;35(suppl 2):S205-12.

12. Quak SH, Furnes R, Lavine J, et al. Obesity in children and adolescents. J Pediatr Gastroenterol Nutr 2008;47:254-9.

13. Fisberg M, Baur L, Chen W, et al. Obesity in children and adolescents: Working Group report of the second World Congress of Pediatric Gastroenterology, Hepatology, and Nutrition. J Pediatr Gastroenterol Nutr 2004;39(suppl 2):S678-87.

14. Koletzko B, Brands B, Grote V, et al. Long-term health impact of early nutrition: the power of programming. Ann Nutr Metab 2017;70:161-9.

15. Koletzko B, Godfrey KM, Poston L, et al. Nutrition during pregnancy, lactation, and early childhood and its implications for maternal and long-term child health: the EarlyNutrition Project recommendations. Ann Nutr Metab 2019;74:93-106.

16. Woo Baidal JA, Locks LM, Cheng ER, et al. Risk factors for childhood obesity in the first 1,000 days: a systematic review. Am J Prev Med 2016;50:761-79.

17. Berti C, Cetin I, Agostoni C, et al. Pregnancy and infants' outcome: nutritional and metabolic implications. Crit Rev Food Sci Nutr 2016;56:82-91.

18. Brands B, Demmelmair H, Koletzko B. The EarlyNutrition Project. How growth due to infant nutrition influences obesity and later disease risk. Acta Paediatr 2014;103:578-85.

19. Koletzko B, Brands B, Chourdakis M, et al. The Power of Programming and The EarlyNutrition project: opportunities for health promotion by nutrition during the first thousand days of life and beyond. Ann Nutr Metab 2014;64:141-50.

20. Grover SA, Kaouache M, Rempel P, et al. Years of life lost and healthy life-years lost from diabetes and cardiovascular disease in overweight and obese people: a modelling study. Lancet Diabetes Endocrinol 2015;3:114-22.

21. Global Burden of Disease Study 2015 Maternal Mortality Collaborators. Global, regional, and national levels of maternal mortality, 19902015: a systematic analysis for the Global Burden of Disease Study 2015. Lancet 2016;388:1775-812.

22. Voerman E, Santos S, Patro Golab B, et al. Maternal body mass index, gestational weight gain, and the risk of overweight and obesity across childhood: an individual participant data meta-analysis. PLoS Med 2019;16:e1002744.

23. Koletzko B, Von Kries R, Monasterolo RC, et al. Infant feeding and later obesity risk. Adv Exp Med Biol 2009;646:15-29.

24. Alexander DD, Cabana MD. Partially hydrolyzed $100 \%$ whey protein infant formula and reduced risk of atopic dermatitis: a meta-analysis. $J$ Pediatr Gastroenterol Nutr 2010;50:422-30.

25. Von Kries R, Koletzko B, Sauerwald T, et al. Breast feeding and obesity: cross sectional study. BMJ 1999;319:147-50.

26. Arenz S, Ruckerl R, Koletzko B, et al. Breast-feeding and childhood obesity-a systematic review. Int $J$ Obes Relat Metab Disord 2004;28:1247-56.

27. Weng SF, Redsell SA, Swift JA, et al. Systematic review and metaanalyses of risk factors for childhood overweight identifiable during infancy. Arch Dis Child 2012;97:1019-26.

28. Horta BL, Victora CG. Long-term Effects of Breastfeeding: A Systematic Review Geneva, Switzerland: World Health Organization; 2013.

29. Yan J, Liu L, Zhu Y, et al. The association between breastfeeding and childhood obesity: a meta-analysis. BMC Public Health 2014;14: 1267. 
30. Kramer MS, Matush L, Vanilovich I, et al. A randomized breastfeeding promotion intervention did not reduce child obesity in Belarus. J Nutr 2009;139:417S-S421.

31. Martin RM, Kramer MS, Patel R, et al. Effects of promoting long-term, exclusive breastfeeding on adolescent adiposity, blood pressure, and growth trajectories: a secondary analysis of a randomized clinical trial. JAMA Pediatr 2017;171:e170698.

32. Ruckinger S, Von Kries R. Breastfeeding and reduced risk of childhood obesity: will randomized trials on breastfeeding promotion give the definite answer? Am J Clin Nutr 2009;89:653-5author reply 5.

33. Koletzko B, Demmelmair H, Grote V, et al. Optimized protein intakes in term infants support physiological growth and promote long-term health. Semin Perinatol 2019;43:151153.

34. Dewey KG, Heinig MJ, Nommsen LA, et al. Growth of breast-fed and formula-fed infants from 0 to 18 months: the DARLING Study. Pediatrics 1992;89 (6 pt 1):1035-41.

35. Azad MB, Vehling L, Chan D, et al. Infant feeding and weight gain: separating breast milk from breastfeeding and formula from food. Pediatrics 2018;142:pii: e20181092.

36. Baird J, Fisher D, Lucas P, et al. Being big or growing fast: systematic review of size and growth in infancy and later obesity. $B M J$ 2005;331:929.

37. Nettleton JA, Jebb S, Riserus U, et al. Role of dietary fats in the prevention and treatment of the metabolic syndrome. Ann Nutr Metab 2014;64:167-78.

38. Rzehak P, Oddy WH, Mearin ML, et al. Infant feeding and growth trajectory patterns in childhood and body composition in young adulthood. Am J Clin Nutr 2017;106:568-80.

39. Heinig MJ, Nommsen LA, Peerson JM, et al. Energy and protein intakes of breast-fed and formula-fed infants during the first year of life and their association with growth velocity: the DARLING Study. Am J Clin Nutr 1993;58:152-61.

40. Alexy U, Kersting M, Sichert-Hellert W, et al. Macronutrient intake of 3- to 36-month-old German infants and children: results of the DONALD Study. Dortmund Nutritional and Anthropometric Longitudinally Designed Study. Ann Nutr Metab 1999;43:14-22.

41. Koletzko B, Von Kries R, Closa R, et al. Lower protein in infant formula is associated with lower weight up to age $2 \mathrm{y}$ : a randomized clinical trial. Am J Clin Nutr 2009;89:1836-45.

42. Weber M, Grote V, Closa-Monasterolo R, et al. Lower protein content in infant formula reduces BMI and obesity risk at school age: followup of a randomized trial. Am J Clin Nutr 2014;99:1041-51.

43. Totzauer M, Luque V, Escribano J, et al. Effect of lower versus higher protein content in infant formula through the first year on body composition from 1 to 6 years: follow-up of a randomized clinical trial. Obesity (Silver Spring) 2018;26:1203-10.

44. Putet G, Labaune JM, Mace K, et al. Effect of dietary protein on plasma insulin-like growth factor-1, growth, and body composition in healthy term infants: a randomised, double-blind, controlled trial (Early Protein and Obesity in Childhood (EPOCH) study). Br J Nutr 2016;115:271-84.

45. Wall CR, Hill RJ, Lovell AL, et al. A multicenter, double-blind, randomized, placebo-controlled trial to evaluate the effect of consuming Growing Up Milk "Lite" on body composition in children aged 1223 mo. Am J Clin Nutr 2019;109:576-85.

46. Blake-Lamb TL, Locks LM, Perkins ME, et al. Interventions for childhood obesity in the first 1,000 days a systematic review. Am J Prev Med 2016;50:780-9.

47. EFSA Panel on Dietetic Products. Scientific opinion on the essential composition of infant and follow-on formulae. EFSA J 2014;12:106.

48. Grote V, Theurich M, Koletzko B. Do complementary feeding practices predict the later risk of obesity? Curr Opin Clin Nutr Metab Care 2012;15:293-7.

49. Koplin JJ, Kerr JA, Lodge C, et al. Infant and young child feeding interventions targeting overweight and obesity: a narrative review. Obes Rev 2019;20(suppl 1):31-44.

50. Dallacker M, Hertwig R, Mata J. The frequency of family meals and nutritional health in children: a meta-analysis. Obes Rev 2018;19:638-53.

51. ESPGHAN Committee on NutritionAgostoni C, Braegger C, Decsi T, et al. . Role of dietary factors and food habits in the development of childhood obesity: a commentary by the ESPGHAN Committee on Nutrition. J Pediatr Gastroenterol Nutr 2011;52:662-9.
52. Bach-Faig A, Berry EM, Lairon D, et al. Mediterranean diet pyramid today. Science and cultural updates. Public Health Nutr 2011;14: 2274-84.

53. Iaccarino Idelson P, Scalfi L, et al. Adherence to the Mediterranean diet in children and adolescents: a systematic review. Nutr Metab Cardiovasc Dis 2017;27:283-99.

54. Wolters M, Joslowski G, Plachta-Danielzik S, et al. Dietary patterns in primary school are of prospective relevance for the development of body composition in two German pediatric populations. Nutrients 2018;10:pii: E1442.

55. Martin-Calvo N, Chavarro JE, Falbe J, et al. Adherence to the Mediterranean dietary pattern and BMI change among US adolescents. Int J Obes (Lond) 2016;40:1103-8.

56. Mithril C, Dragsted LO, Meyer C, et al. Guidelines for the new nordic diet. Public Health Nutr 2012;15:1941-7.

57. Geserick M, Vogel M, Gausche R, et al. Acceleration of BMI in early childhood and risk of sustained obesity. $N$ Engl $J$ Med 2018;379:1303-12.

58. Deren K, Weghuber D, Caroli M, et al. Consumption of sugarsweetened beverages in paediatric age: a position paper of the European Academy of Paediatrics and the European Childhood Obesity Group. Ann Nutr Metab 2019;74:296-302.

59. Bayer O, Von Kries R, Strauss A, et al. Short- and mid-term effects of a setting based prevention program to reduce obesity risk factors in children: a cluster-randomized trial. Clin Nutr 2009;28:122-8.

60. Williams J, Scarborough P, Matthews A, et al. A systematic review of the influence of the retail food environment around schools on obesityrelated outcomes. Obes Rev 2014;15:359-74.

61. Luque V, Escribano J, Closa-Monasterolo R, et al. Unhealthy dietary patterns established in infancy track to mid-childhood: the EU Childhood Obesity Project. J Nutr 2018;148:752-9.

62. Marques A, Minderico C, Martins S, et al. Cross-sectional and prospective associations between moderate to vigorous physical activity and sedentary time with adiposity in children. Int J Obes (Lond) 2016;40:28-33.

63. Moliner-Urdiales D, Ruiz JR, Ortega FB, et al. Association of objectively assessed physical activity with total and central body fat in Spanish adolescents; the HELENA Study. Int $J$ Obes (Lond) 2009;33:1126-35.

64. Hnatiuk JA, Brown HE, Downing KL, et al. Interventions to increase physical activity in children 0-5 years old: a systematic review, metaanalysis and realist synthesis. Obes Rev 2019;20:75-87.

65. Brown HE, Atkin AJ, Panter J, et al. Family-based interventions to increase physical activity in children: a systematic review, metaanalysis and realist synthesis. Obes Rev 2017;18:491-4.

66. Borde R, Smith JJ, Sutherland R, et al. Methodological considerations and impact of school-based interventions on objectively measured physical activity in adolescents: a systematic review and meta-analysis. Obes Rev 2017;18:476-90.

67. Norris E, Hamer M, Stamatakis E. Active video games in schools and effects on physical activity and health: a systematic review. J Pediatr 2016;172:40.e5-6.e5.

68. Ip P, Ho FK, Louie LH, et al. Childhood obesity and physical activityfriendly school environments. J Pediatr 2017;191:110-6.

69. Tahir MJ, Willett W, Forman MR. The association of television viewing in childhood with overweight and obesity throughout the life course. Am J Epidemiol 2019;188:282-93.

70. Van Grieken A, Ezendam NP, Paulis WD, et al. Primary prevention of overweight in children and adolescents: a meta-analysis of the effectiveness of interventions aiming to decrease sedentary behaviour. Int $J$ Behav Nutr Phys Act 2012;9:61.

71. Ghobadi S, Hassanzadeh-Rostami Z, Salehi-Marzijarani M, et al. Association of eating while television viewing and overweight/obesity among children and adolescents: a systematic review and meta-analysis of observational studies. Obes Rev 2018;19:313-20.

72. Sardinha LB, Marques A, Minderico C, et al. Cross-sectional and prospective impact of reallocating sedentary time to physical activity on children's body composition. Pediatr Obes 2017;12:373-9.

73. Hjorth MF, Chaput JP, Ritz C, et al. Fatness predicts decreased physical activity and increased sedentary time, but not vice versa: support from a longitudinal study in 8- to 11-year-old children. Int $J$ Obes (Lond) 2014;38:959-65. 
74. Reilly JJ, Hughes AR, Gillespie J, et al. A Physical activity interventions in early life aimed at reducing later risk of obesity and related non-communicable diseases: a rapid review of systematic reviews. Obes Rev 2019;20(suppl 1):61-73.

75. Barnett TA, Kelly AS, Young DR, et al. Sedentary behaviors in today's youth: approaches to the prevention and management of childhood obesity: a scientific statement from the American Heart Association. Circulation 2018;138:e142-59.

76. Darling N, Steinberg L. Parenting style as context: an integrative model. Psychol Bull 1993;113:487-96.

77. Arlinghaus KR, Vollrath K, Hernandez DC, et al. Authoritative parent feeding style is associated with better child dietary quality at dinner among low-income minority families. Am J Clin Nutr 2018;108:730-6.

78. Rhee KE, Jelalian E, Boutelle K, et al. Warm parenting associated with decreasing or stable child BMI during treatment. Child Obes 2016;12:94-102.

79. Brown CL, Halvorson EE, Cohen GM, et al. Addressing childhood obesity: opportunities for prevention. Pediatr Clin North Am 2015;62:1241-61.

80. Melis Yavuz H, Selcuk B. Predictors of obesity and overweight in preschoolers: the role of parenting styles and feeding practices. Appetite 2018;120:491-9.

81. Eneli IU, Tylka TL, Watowicz RP, et al. Targeting feeding and eating behaviors: development of the feeding dynamic intervention for caregivers of 2- to 5-year-old children. J Obes 2015;2015:964249.

82. Lederer AM, King MH, Sovinski D, et al. The impact of family rules on children's eating habits, sedentary behaviors, and weight status. Child Obes 2015;11:421-9.

83. Verrotti A, Penta L, Zenzeri L, et al. Childhood obesity: prevention and strategies of intervention. A systematic review of school-based interventions in primary schools. J Endocrinol Invest 2014;37:1155-64.

84. Population-based Prevention Strategies for Childhood Obesity: Report of a WHO Forum and Technical Meeting. World Health Organization: Geneva; December 15-17, 2009.2010.

85. Hesketh KD, Campbell KJ. Interventions to prevent obesity in 0-5 year olds: an updated systematic review of the literature. Obesity (Silver Spring, Md) 2010;18(suppl 1):S27-35.

86. De Silva-Sanigorski AM, Bell AC, Kremer P, et al. Reducing obesity in early childhood: results from Romp \& Chomp, an Australian community-wide intervention program. Am H Clin Nutri 2010;91:831-40.

87. Jones RA, Lubans DR, Morgan PJ, et al. School-based obesity prevention interventions: practicalities and considerations. Obes Re Clin Pract 2014;8:e497-510

88. Brown V, Ananthapavan J, Sonntag D, et al. The potential for longterm cost-effectiveness of obesity prevention interventions in the early years of life. Pediatr Obes 2019;14:e12517.

89. Sonntag D, De Bock F, Totzauer M, et al. Assessing the lifetime costeffectiveness of low-protein infant formula as early obesity prevention strategy: the CHOP randomized trial. Nutrients 2019;11:pii: E1653.

90. Kerr JA, Loughman A, Knox A, et al. Nutrition-related interventions targeting childhood overweight and obesity: a narrative review. Obes Rev 2019;20(suppl 1):45-60.

91. Interventions on Diet and Physical Activity: What Works: Summary Report. Geneva, Switzerland: World Health Organization; 2009.

92. Sanigorski AM, Bell AC, Kremer PJ, et al. Reducing unhealthy weight gain in children through community capacity-building: results of a quasi-experimental intervention program, be active eat well. Int J Obes (Lond) 2008;32:1060-7.

93. Consortium to Lower Obesity in Chicago Children. 2012. Blueprint for accelerating progress in childhood obesity prevention in Chicago: The next decade 2012. http://www.clocc.net/about-us/blueprint/. Accessed March 19, 2020.
94. Forward DuPage. (2018). Forward together we will: 2018 annual report 2018. http://nebula.wsimg.com/0f904bebae554e50aefb72fa51 ea8027? Access KeyId=74AC09CCOC10AAB2269C\&disposition=0\& alloworigin $=1$

95. Wang Y, Cai L, Wu Y, et al. What childhood obesity prevention programmes work? A systematic review and meta-analysis. Obes Rev 2015; 16:547-65.

96. Kunin-Batson AS, Seburg EM, Crain AL, et al. Household factors, family behavior patterns, and adherence to dietary and physical activity guidelines among children at risk for obesity. $J$ Nutr Educ Behav 2015;47:206-15.

97. Fakhouri TH, Hughes JP, Brody DJ, et al. Physical activity and screentime viewing among elementary school-aged children in the United States from 2009 to 2010. JAMA Pediatr 2013;167:223-9.

98. Wen LM, Baur LA, Simpson JM, et al. Sustainability of effects of an early childhood obesity prevention trial over time: a further 3-year follow-up of the healthy beginnings trial. JAMA Pediatr 2015;169:543-51.

99. Whelan J, Love P, Millar L, et al. Sustaining obesity prevention in communities: a systematic narrative synthesis review. Obes Rev 2018;19:839-51.

100. Hoelscher DM, Butte NF, Barlow S, et al. Incorporating primary and secondary prevention approaches to address childhood obesity prevention and treatment in a low-income, ethnically diverse population: study design and demographic data from the Texas Childhood Obesity Research Demonstration (TX CORD) study. Child Obes 2015;11:71-91.

101. De Henauw S, Huybrechts I, De Bourdeaudhuij I, et al. Effects of a community-oriented obesity prevention programme on indicators of body fatness in preschool and primary school children. Main results from the IDEFICS study. Obes Rev 2015;16(suppl 2):16-29.

102. Brown V, Ananthapavan J, Veerman L, et al. The potential costeffectiveness and equity impacts of restricting television advertising of unhealthy food and beverages to Australian children. Nutrients 2018;10:pii: E622.

103. Hawkes C, Smith TG, Jewell J, et al. Smart food policies for obesity prevention. Lancet 2015;385:2410-21.

104. Cabrera Escobar MA, Veerman JL, Tollman SM, et al. Evidence that a tax on sugar sweetened beverages reduces the obesity rate: a metaanalysis. BMC Public Health 2013;13:1072.

105. Smed S, Scarborough P, Rayner M, et al. The effects of the Danish saturated fat tax on food and nutrient intake and modelled health outcomes: an econometric and comparative risk assessment evaluation. Eur J Clin Nutr 2016;70:681-6.

106. Barrientos-Gutierrez T, Zepeda-Tello R, Rodrigues ER, et al. Expected population weight and diabetes impact of the 1-peso-per-litre tax to sugar sweetened beverages in Mexico. PLoS One 2017; 12:e0176336.

107. Epstein LH, Jankowiak N, Nederkoorn C, et al. Experimental research on the relation between food price changes and foodpurchasing patterns: a targeted review. Am J Clin Nutri 2012;95:789-809.

108. Talati Z, Egnell M, Hercberg S, et al. Food choice under five front-ofpackage nutrition label conditions: an experimental study across 12 countries. Am J Public Health 2019;109:e1-6.

109. Egnell M, Ducrot P, Touvier M, et al. Objective understanding of Nutri-Score Front-Of-Package nutrition label according to individual characteristics of subjects: comparisons with other format labels. PLoS One 2018;13:e0202095.

110. Vyth EL, Steenhuis IH, Roodenburg AJ, et al. Front-of-pack nutrition label stimulates healthier product development: a quantitative analysis. Int J Behav Nutr Phys Act 2010;7:65. 